\title{
Effect of call-clubs to institute local network effects in mobile telecommunication and its' implications on brand loyalty
}

\author{
E.A.C.P. KARUNARATHNE \\ Huazhong University of Science and Technology, Wuhan, P.R. China \\ Wayamba University of Sri Lanka, Kuliyapitiya, Sri Lanka \\ chami@wyb.ac.lk \\ Zhang JING \\ Huazhong University of Science and Technology, Wuhan, P.R. China
}

\begin{abstract}
As a result of rapid technological advancements in the mobile telecommunication industry, many firms have set their strategies to target larger customer bases since it forecasts extensive future profit generation. Due to severe competition, while employing successful customer loyalty strategies, customer locked-in strategies are also commonly used in the telecommunication industry to retain their customers within the firm. Call-clubs benefits are one of the commonly used strategies used to create local network effects in the mobile telecommunication market place. Thus, this paper targets to provide insight on the implication of subscriber's involvement in call-clubs on their loyalty towards service providers. A survey based quantitative approach was followed for this study and the data was gathered through a structured off-line questionnaire from randomly selected mobile users in Sri Lanka. Based on collected valid responses, analysis was carried out to answer the designed research hypotheses and structural equation modelling techniques were mainly used for statistical analysis. As per the analysis, research model shows a fairly high level of explanatory power with customer loyalty and perceived call-clubs benefits which indicate customers' preference towards the service provider when most frequently contacting parties are using the same network. Further analysis was carried out to investigate the moderating effect on call-clubs benefits and customer loyalty relationships due to two main technological advancements; namely, Internet based voice calling facility and multiple connection access facility. Based on the analysis results recommendations were made to track the value of call-clubs strategies accordingly.
\end{abstract}

Keywords: local network effects, customer loyalty, call-clubs, relationship age, technology advancements

Please cite the article as follows: Karunarathne, E.A.C.P and Jing, Z. (2017), "Effect of call-clubs to institute local network effects in mobile telecommunication and its' implications on brand loyalty", Management \& Marketing. Challenges for the Knowledge Society, Vol. 12, No. 1, pp. 6177. DOI: $10.1515 / \mathrm{mmcks}-2017-0005$.

\section{Introduction}

Day by day, the mobile telecommunication market is facing drastic changes due to technological innovations in the industry. These innovations have contributed much to the industry growth in recent years. Further, the recent increase in technological convergence of voice, video, and data has led service providing firms into severer competition, while enabling a wide range of services to subscribers (Srinuan et al., 2014). According to Lee et al. (2015), the rapid expansion of the mobile service market was spurred by the wide availability of high-speed telecommunication 
networks and wireless Internet services. These indicate subscribers' extensive use of mobile services than telephony. To meet these subscribers' diverse requirements and expectations, todays' mobile devices are particularly designed and intended for individuals (Boakye, 2015). As a result of these market changes, company profits through telephony have significantly declined though all the service providers are up to date in technological adoption perspective in the market place. But, this has created a new environment for service providers to become the platform supplier for data channels which forecasts extensive future profit generation (GSMA, 2016). Further, as per the industry analysts, to grab such opportunity and to win market competition, service providers need to maintain healthy customer network. According to Maicas et al. (2009) and Farrell and Klemperer (2007), both the size and the stability of the customer base that they are operating have been identified as main profitability driven factors in high technology involving markets such as mobile telecommunication. Therefore, service providers are needed to implement new strategies to retain their customers while grabbing new ones to the network. According to the Kotler and Keller (2006), even from financial perspective, retention is important because firms spend more than five times as much to obtain a new customer than to retaining an existing one. On the other hand, it is reviled that five percent in customer retention leads to an increase of 25 percent to 85 percent in profits, depending on the industry (Li and Robert, 2011; Kerin et al., 2009; Reichheld and Sasser, 1990). Similar phenomenon has verified by Reicheld and Sasser (1990), and they have stated that the businesses may increase their profits by $100 \%$ if the retention rate goes up by $5 \%$.

In the mobile telecommunication industry, the main condition to retain subscriber base is to win customer loyalty, a key necessity for the long-term maintenance of the brand's life (Serkan and Gorhan, 2004). On the other hand, while employing successful customer loyalty strategy, customer locked-in strategies are also commonly used in the telecommunication industry to retain the customers within the firm. Due to severe competition and reaching saturation level, it is vital to have a defensive strategy which strives to retain existing customers, than an aggressive one, which expands the size of the overall market by inducing potential customers in the established mobile telecommunication industry (Fornell, 1992; Ahmad and Buttle, 2002). On the other hand, such a strategy is possible as the telecommunication market is one of best examples of network industries. The users of such a network facility value the "size of a particular network" as an additional source of benefit, which is the basis of "network effect" (Sobolewski and Czajkowski, 2012). The presence of strong network effect will enable to retain customers within their network for a longer period of time. The underlying reason to join such networks is to gain the benefits of on-net calls with subscriber's socio economic groups which are known as call clubs (Haucap and Heimeshoff, 2011).

In Sri Lanka, currently five mobile service providing firms are operating in a market where mobile telephone penetration stood at 116 percent by the end of 2015 (Central Bank of Sri Lanka, 2016). Further, the mobile telecommunication market has shown its maturity level by indicating a fall in the rate of annual increase in subscriber numbers. In terms of size and technology, the mobile communications sector has 
developed rapidly in the past few years. These advanced technological developments are comparable with that of any advanced country.

On the other hand, unavailability of mobile number portability mechanism has made it easy for service providing firms to enjoy a locked-in environment in the Sri Lankan market. Since service providers have a more interesting business environment to carry out customer locked-in strategies, firms have given significant on-net price discounts to subscribers to establish their own call clubs within firms. But there is no evidence to prove the existence of local network effects due to the effect of call-clubs in the Sri Lankan market or call-clubs implications towards brand loyalty.

Due to recent technological advancements in the industry, mobile subscribers have received many opportunities to skip these locked-in models. Such approaches have become possible as many of these new developments are independent from service providers; therefore, subscribers can get use these services without changing already connected service provider. Mobile voice over internet protocol (mVoIP) application usage and multiple connection access facility are two of such developments that are already popular in the mobile telecommunication industry. That has been evidenced even in the Sri Lankan market. According to the Sri Lanka Telecom 2014 annual report, approximately a fifth of mobile subscribers are using multiple mobile connections. It is obvious that these two facilities are capable of weakening call-clubs based customer locked-in scenarios. Therefore, providing insight on moderating the impact of above discussed two basic technological advancements would be an interesting investigation both from a theoretical and a managerial perspective.

\section{Effect of calling clubs in the mobile telecommunication industry}

In mobile telecommunication, a common peer-to-peer network effect is that customers receive benefits by every adoption in the particular network (Farrell and Klemperer, 2007). However, in practically these network effects are localized. According to Karacuka et al. (2013), local network effects are significant for consumer choice as consumers are more likely to be affected by the choices of other people within their local area than by the overall size of a network. For example, a mobile subscriber gains more benefits when his family or friend adopts the same network than when strangers do so. Due to many reasons, both members are benefited by such an adoption. Furthermore, the above idea has also been identified by Sobolewski and Czajkowski (2012), in their study on network effects in the Polish telecommunication market. Through their findings, they have concluded that the total number of subscribers in the network was not an essential attribute, but rather the number of people whom consumers call mostly such as family members and friends.

According to each subscriber's individual emotional relation with other parties, three exclusive groups, namely family, friend and others, have been identified by the Sobolewski and Czajkowski (2012) in their study in mobile telecommunication industry. This group classification was done based on the way that subscriber value other parties' presence in a particular mobile network when selecting a service provider. Classification of the three call-clubs was done as follows: 
- Family: people, such as parents, siblings, partners, and other people, who are not necessarily family, but are considered to be 'the closest'.

- Friends: all persons, with whom the respondent maintains regular contact, such as friends, acquaintances, and relatives, who were not classified as the family.

- Others: all other people whom respondents contact irregularly, such as shops, offices, distant friends, or does not contact at all, but are still connected to the same network. This attribute was basically equivalent to each operator's customer base.

Discounted call rates within the same network is one of the major reasons for subscribers to prefer particular network than others where the number portability facility is not available. In the mobile telecommunication industry, all mobile telecommunication service providers are inter-connected as they have to offer the calling facility to the subscribers of any other network. But, in the past few decades, technological advancements in the industry helped service providers to reduce the communication cost drastically. As a result, service providing firms have adopted new pricing strategies to retain their subscribers within the firm and to attract new set of customers who are most frequently contacted by particular subscriber which is denoted by call clubs. This strategy was focused to offer huge on-net call benefits to subscribers. This allowed firms not only to attract new ones but also to lock-in set of customers within the same network. The effect created through the differentiation between on-net and off-net call rates has been denoted as "tariff-mediated network effects" (Haucap and Heimeshoff, 2011). Further, except to the on-net price discounts, subscriber's usage profile, network distribution of their most frequently called parties, and many other market-specific and user-specific factors have been identified as local network effect denoting factors in mobile telecommunication (Liikanen et al., 2004; Sobolewski and Czajkowski, 2012). Even in Sri Lanka, such a significant off-net and on-net price differences can be seen among all service providing firms. Many service providers have offered several call plans which enable group of subscribers to initiate call-clubs to gain maximum benefits. Therefore, on-net call benefits and call-clubs benefits were considered as influential factors for call-clubs to investigate its' impact on their loyalty towards service providing firms.

\section{Customer loyalty in the mobile telecommunication industry}

Customer loyalty plays a vital role in an organization's success. The significance of customer loyalty is that it closely relates to the company's continued survival, and to strong future growth (Kim et al., 2004). And from a firm profitability perspective, loyal customers are main sources of increased profitability. Usually loyal customers are willing to spend more and may serve as enthusiastic advocates for the organization (Harris and Goode, 2004). On the other hand, as loyal customers stick to firm offerings, companies do not need to have heavy promotions targeting this group of customers. They help the continuous flow of income to the organizations through repeat buying and also increased purchases. But, it is far more than repeat business since they believe firm's offering as their best option. Also, loyal customers are used to 
taking the company offer whenever they are faced with purchasing decision on a product category that the company offers. Moreover, loyalty means stay with a loyal brand or a product even when there may be issues with service offering. Due to many uncertainties in an intense competitive mobile telecommunication market, there is a higher probability for such issues to occur. But even in such a situation, loyal customers would like to wait and see the response from service provider even if they are approached by competitors. It implies that loyal customers are not interested on competitors and are willing to support service provider to overcome any weaknesses as the organization has been good to them in the past in addressing such issues.

According to the Johnson et al. (2006), customer loyalty is likely to influence a customer's willingness to stay, repurchase probability, and the likelihood that they will recommend the brand. Further, several researchers have identified customer loyalty as a key component for a brand's long-term viability (Amin et al., 2012; Chen et al., 2010; Krishnamurthi and Raj, 1991). Furthermore, the importance of customer loyalty has identified in continuous service settings like mobile telecommunication due to customers' variety-seeking behaviours and its' extensive competing environment (Karjaluoto et al., 2012; Johnson et al., 2006; Verhoef, 2003). According to Lee et al. (2015) retaining subscribers within the firm and motivating the repeat purchasing of mobile services are very crucial for all mobile service providers.

As per Oliver (1993), customer loyalty is a behavioural and attitudinal predilection to stay with the seller in the long-term. According to studies by Bove et al. (2009), Jones and Taylor (2007), Kumar et al. (2006), Lam et al. (2004), and Fullerton (2005), there are two kinds of loyalty; namely, behavioural loyalty and attitudinal loyalty. This is the most common classification of customer loyalty used in many literatures.

Consumers' repurchase behavioural or intension of specific brand is described as behavioural loyalty (Russell-Bennett et al. 2007). This ensures future purchase of company offer and indicates transforming possibility of customer loyalty into actual purchase. Usually, continuous or frequent purchase behaviour, recommendations on firm's offerings, and customer preferences for company offers/ product categories have been identified as dimensions of behavioural loyalty (Hallowel, 1996). On the other hand, consumers' sense of specific products or service has been described as attitudinal loyalty (Kumar and Reinartz, 2006). Meantime, several authors have suggested to include both aspects of loyalty to measure overall true loyalty (Kim et al., 2004; Soderlund, 2003; Dick and Basu 1994) Therefore, for this study, loyalty was identified as a combination of both attitudinal and behavioral loyalties.

\section{Development of hypotheses}

This paper targets to provide insight on the implication of subscriber's perception of call-clubs on customer loyalty in the mobile telecommunication industry. Strategically, call-clubs have played a major role in mobile telecommunication in the past few decades. Even though firms have identified its' importance, due to recent rapid developments in mobile telecommunication market, it is challenging to identify impactions of call-clubs in todays' market. Therefore, from a theoretical and a managerial perspective, understanding the relationship among these two vital factors 
in today's mobile telecommunication industry would be an interesting investigation. Importantly, assessment of this relationship's success and failure in todays' competitive market will enable firms to track the value of call-clubs and strategies that can be modified accordingly.

With reference to the above discussed literature on customer loyalty and callclubs in mobile telecommunication, the following hypotheses were formulated in this study. Proposed research study was carried out while controlling mobile subscribers' age, income and education level.

H1. There will be a positive relationship between perceived call-clubs in mobile telecommunication and their loyalty towards service provider.

H2. Subscribers' monthly mobile expenditure on mobile positively moderates the positive effect of perceived call-clubs and customer loyalty in mobile telecommunication.

H3. Relationship age positively moderates the positive effect of perceived callclubs and customer loyalty in mobile telecommunication.

Furthermore, subscribers' acceptance of technological advancements, namely mVoIP application usage and multiple connection usage moderating the above relationship will also be investigated.

H4. Mobile subscribers' usage of mVoIP applications positively moderates the positive effect of perceived call-clubs and customer loyalty in mobile telecommunication.

H5. Mobile subscribers' usage of multiple mobile connections moderates the positive effect of perceived call-clubs and customer loyalty in mobile telecommunication.

\section{Methodology}

Data collection

Survey based quantitative approach was followed to find out the implications of calling clubs on their perceptions of loyalty towards mobile service providers. The study was preceded with a random sampling among mobile subscribers residing in Sri Lanka. The data was gathered through a structured off-line questionnaire from randomly selected mobile users in Sri Lanka. Total of 800 questionnaires were distributed and among that 734 responses were obtained through a data collection process which lasted for four weeks in February 2016. Among the collected data set, 692 valid responses, excluding those with omissions or with randomly repeated answers were taken for the analysis of the research hypotheses.

The initial part of the questionnaire contained several socio-demographic questions to get a basic idea on sample profile. Based on the descriptive analysis of sample profile, a total of $39.9 \%$ of the questionnaire respondents were male mobile subscribers. In terms of mobile users' income, $47.7 \%$ subscribers are earning less than Rs. 20,000 per month, $28.9 \%$ in between Rs. 20,000 to Rs. 40,000 and $23.4 \%$ subscribers earn more than Rs. 40,000. Among the sample 73.3\% subscribers use prepaid connections which is almost equal to the population pre-paid connection penetration. Among this sample $24 \%$ subscribers recently got connected to users who 
are having less than two years of age. Interestingly, 31.4\% subscribers are using their mobile connection for more than six years. In the context of age category, $14.7 \%$ of subscribers are less than 21 years old, while $11.1 \%$ represent the over 40 years old category. From the education perspective $50.7 \%$ of the participants are involved with higher studies after schooling. Among that group $37.7 \%$ of subscribers have bachelors' degree or above qualification. The sample consists $49 \%$ of users who are using multiple mobile connections. Also, 50.9\% of users are using mVoIP applications to communicate with each other, apart from service providers' voice calling facility.

\section{Variables and measurement scales}

The identified constructs of the model were measured using a multiple-item measurement scale. A five-point Likert-point scale was employed for all items, ranging from strongly disagree to strongly agree. The measures for customer loyalty adapted previously were validated questionnaires, especially focusing on studies conducted in the mobile telecommunication industry. Measurement of calling-clubs was defined based on referring several past studies. As the measure of call-clubs benefits have not been validated previously, validation for that part is required. As the survey was carried out in Sri Lanka, the designed English language questionnaire was professionally translated into the local language (Sinhala) to easily collect the feedback from the general community. Questionaries' conceptual equivalence was ensured by translating the questionnaire several times into both Sinhala and English language (Mullen, 1995).

To measure dependent variable customer loyalty, the measurement scale developed by Karjaluoto et al. (2012) in their study in telecommunication industry was mainly adopted. The scale covered both attitudinal and behavioural aspects of loyalty and scale was designed to measure it separately. Items used to measure both behavioural loyalty and attitudinal loyalty is rated five-point Likert-type scales and five items scale is used for each loyalty factor. Karjaluoto et al. (2012) attitudinal loyalty measurement scale which was applied in mobile telecommunication was derived from the study undertaken by Harris and Goode (2004) in which Oliver's (1997, 1999) four-stage loyalty framework applied. The cognitive, affective and conative aspects of loyalty were included in this scale. The scales developed by Zeithaml et al. (1996) and Garbarino and Johnson (1999) and applied in Karjaluoto et al. (2012) in the telecommunication industry were adapted to measure behavioural loyalty.

Impact of calling clubs was measured referring to two sub sets; calling club benefits and on-net call benefits separately. As there wasn't any previously used measuring scale, new scale was developed refereeing past literature related to call club and on-net benefits. Call club benefits were measured using the four-item scale, and measured using five-point Likert-type scales. The call club benefits construct is operationalized by asking to rate based on the benefits received from the presence of most frequently contacting parties in a particular network. The value of most frequently contacting parties' presence, impact when selecting a network, perceived benefits and reasoning to continue are the items used to measure calling club benefits. On the other hand, to measure implications of on-net benefits, five-point Likert-type 
scales were adopted and measured using a three-item based scale developed by referring to implications of on-net benefits in past studies. This construct is operationalized by referring to subscriber's perception of on-net call benefits when selecting perceived benefits via on-net call rates, and on-net call rate's impact to continue with the same network. Reliability and validity of this scale was measured following several statistical tests before continue to the analysis of the model.

\section{Results and discussion}

\section{Measurement model}

To check the reliability of our data, internal consistency of the sample was analysed. Both call-club benefits and customer loyalty scales are first subjected to a series of exploratory factor analyses. For the scale used for call-club benefits, Maximum Likelihood factoring estimation via the Promax rotation as the orthogonal rotation method were employed and the results reveal that the call-club benefits scale has two dimensions in line with the design. Test applied to measure sampling adequacy, Kaiser-Meyer-Olkin (KMO) value 0.853 , indicate meritorious sample adequacy for the test. The model has explained $61.91 \%$ total variance and pattern matrix indicate all most all factor loading over 0.7. From customer loyalty scale perspective, the output revealed two loyalty dimensions as expected and the two-factor solution explains $59 \%$ of the variance. Even though item number five of the attitudinal loyalty has shown some issues with the model. Therefore, that item was dropped from further analysis as it caused issues to the research model. Careless responses or un-matching scenario to Sri Lankan market conditions might be reasons for above behaviour. Finally, factor analysis results show possibility to go further analysis by considering call-club benefits and loyalty as second order latent constructs in the structural model. After eliminating items which caused issues to the model, the reliability analysis of each factor was performed. Results indicate a sound reliability level by getting over 0.7 Cronbach's alpha value for all factors examine (Call-clubs benefits $=0.863$, loyalty $=$ 0.890).

Thereafter, to analyse the constructs' validity, a confirmatory factor analysis (CFA) was performed with the measurement model. This analysis assesses whether the measuring tools have exactly measured the concepts in the study. Goodness of fit $(\mathrm{GFI})=0.977$, adjusted goodness of fit $(\mathrm{AGFI})=0.963$, root mean square residual $(\mathrm{RMR})=0.021$, normed fit index $(\mathrm{NFI})=0.975$ and comparative fit index $(\mathrm{CFI})=0.991$ indicated that they generally satisfied validity evaluation standards. Details are shown below in Table 1.

Table 1. Index of fit of the model

\begin{tabular}{|l|c|c|c|c|c|c|c|c|c|}
\hline Index of fit & $\begin{array}{c}\text { Chi- } \\
\text { Square }\end{array}$ & (df) & P & CMIN/DF & GFI & AGFI & NFI & CFI & RMSEA \\
\hline Value & 130.82 & 85 & .001 & 1.539 & .977 & .963 & .975 & .991 & .028 \\
\hline
\end{tabular}

RMSEA - root mean square error of approximation

Source: Authors' own research.

Further, unidimensionality is a necessary condition for reliability and construct validation (Mak and Sockel, 2001). Thus, for each construct, unidimensionality was analysed. According to Joreskog and Sorbom (1993), GFI should stand at 0.90 or 
above for unidimensionality. Consumer loyalty GFI (0.998) and call-club benefits GFI (0.993) suggest that each of the constructs are unidimensional. Further, to test the convergent validity of the constructs, Bentler-Bonett NFI was examined. Consumer loyalty NFI (0.998) and call-club benefits NFI (0.993) indicate convergent validity in both constructs used in the study.

An additional step was followed to further check for discriminant validity as recommended by Fornell and Larcker (1981): The average variance extracted (AVE) and share variance estimates (squared correlation) were compared between each pair of factors. Results showed that AVEs were higher than share variance estimates in all cases.

\section{Structural model}

Structural equation modelling was developed to assess the statistical significance of the research proposed relationship between calling-clubs benefits and customer loyalty. Results of the empirical casual model are shown below in Figure 1. Structural model's acceptance was measured using common model fit criteria used in AMOS such as chi-square test statistic, CMIN/DF, GFI, AGFI, RMR, NFI, CFI and RMSEA. All of the obtained fit measures indicated that the structural model was acceptable (Chisquare $=202.611 ; \mathrm{p}<.000 ; \mathrm{CMIN} / \mathrm{DF}=1.547, \mathrm{GFI}=0.971 ; \mathrm{AGFI}=0.957 ; \mathrm{RMR}=0.36$; $\mathrm{NFI}=0.965$; CFI $=0.987$; RMSEA $=0.028$ ). In structured model, while simulating the relationship, demographic factors such as subscriber's age, income and education were controlled.

Chi-square $=202.611$

Degrees of freedom $=131$

Probability level $=.000$

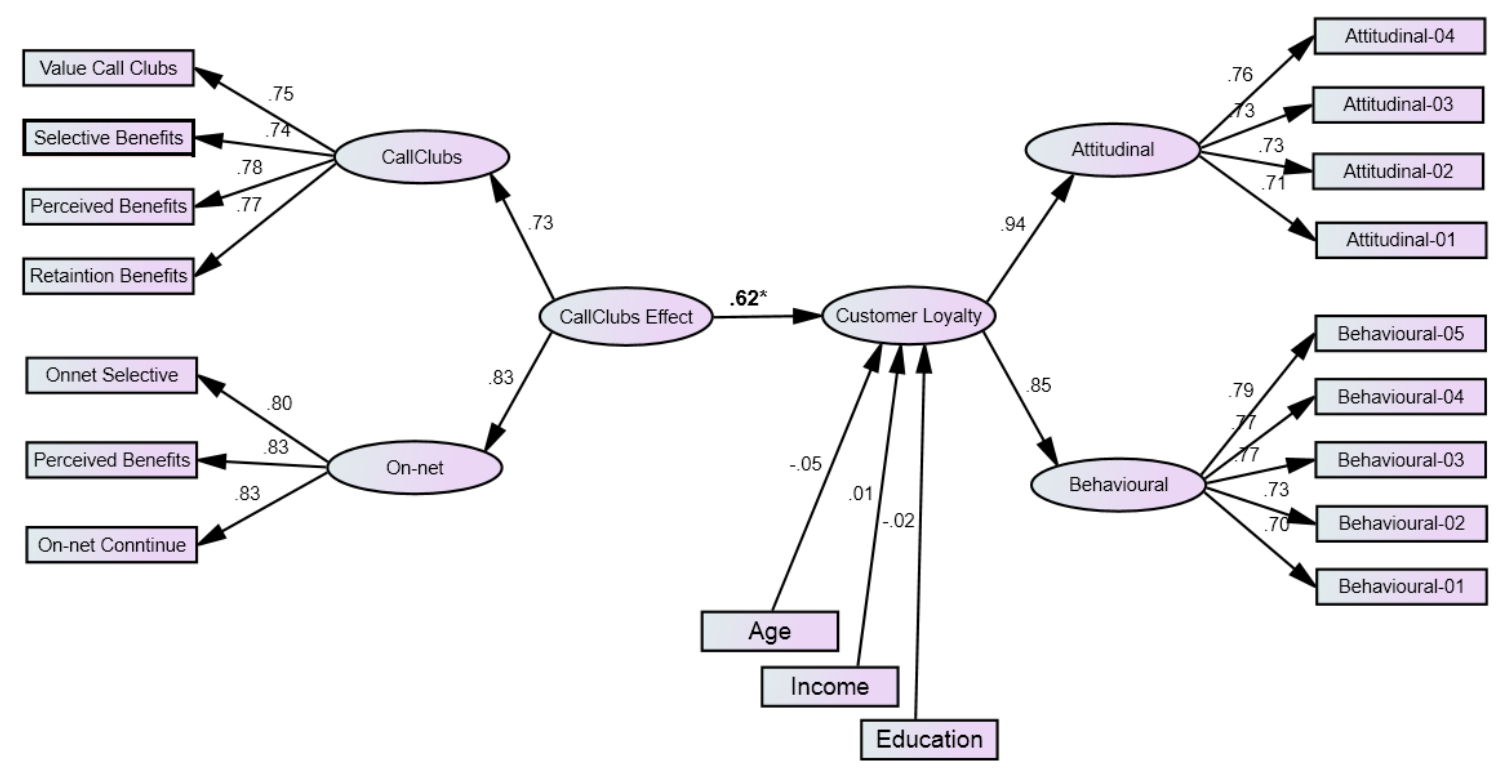

Figure 1. The results of the empirical causal model (SEM)

Source: Authors' own research. 


\section{Hypothesis testing}

H1. There will be a positive relationship between call-club benefits and customer loyalty in mobile telecommunication.

In this study, for hypothesis $\mathrm{H} 1$, the relationship between call-clubs benefits and customer loyalty is investigated. For this, the data was analysed by path analysis. In accordance with the parameter estimates, results of the path analysis show that callclubs benefits were positively and significantly related to customer loyalty ( $p>0.01)$. In other words, according to the test results, the regression weight for call-clubs benefits in the prediction of customer loyalty is significantly different from zero at the 0.001 level (two-tailed). Thus, the null hypothesis of no positive relationship between call-clubs benefits and customer loyalty was rejected as the significant level is less than 0.05 . Further, the model shows a fairly high level of explanatory power with customer loyalty and perceived call-clubs benefits having squared multiple correlation (SMC) value of 0.62 . It implies that when call-clubs benefits goes up by 1 standard deviation, customer loyalty goes up by 0.62 standard deviations.

H2. Mobile subscribers' monthly mobile expenditure moderates the positive effect of perceived call-club benefits and customer loyalty in mobile telecommunication.

To test above mentioned moderating effect of monthly mobile expenditure, the relationship between call-clubs benefits and customer loyalty was examined using nested group path analysis in structural equation modelling. Based on subscribers' monthly expenditure on mobile, subscribers were categorized into two groups; namely, low spending subscribers and high spending subscribers. In accordance with the parameter estimates, results of the nested group examination of path analysis indicate non-significant difference among these two groups $(p=0.232)$ at significant level of 0.05 . Thus, there is not enough evidence to reject the null hypothesis relating to the moderating effect on the relationship between positive call-clubs benefits and customer loyalty at the significant level 0.05 . Even though, when considering these two groups as two separate models, high spending user group has shown statistically significant 0.61 standard regression weights, while low spending user group indicated 0.65 standard regression weights. Interestingly, in both cases the relationships were statistically significant and results are shown below in Table 2 . This implies an increasing higher level of explanatory power with customer loyalty and perceived call-club benefits when their monthly mobile expenditure is low.

Table 2. Regression weights of the relationship among perceived call-clubs benefits and customer loyalty on subscriber's monthly mobile expenditure

\begin{tabular}{|l|r|r|r|r|r|}
\hline & \multicolumn{6}{|c|}{ Regression Weights } & \multicolumn{2}{|c|}{ Structural weights } \\
\cline { 2 - 6 } & Estimate & S.E. & C.R. & P & \multicolumn{2}{c|}{ Estimate } \\
\hline Low Spending Users & .943 & .148 & 6.364 & $* * *$ & .650 \\
\hline High Spend Users & .732 & .107 & 6.868 & $* * *$ & .609 \\
\hline
\end{tabular}

*** absolute $p$ value is less than 0.001

Source: Authors' own research. 
H3. Relationship age positively moderates the positive effect of perceived call-club benefits and customer loyalty in mobile telecommunication.

Effect of relationship age on the relationship between perceived call-club benefits and customer loyalty was examined using multiple group path analysis in AMOS to test the above mentioned moderating effect. For the analysis, the relationship age of subscribers was categorized into two groups, based on the time period that they connected with particular service provider. Subscribers using particular mobile connection for less than two years were named as low relationship age group and others named as high relationship age group. According to the results of the nested group examination of path analysis, the significant difference among these two groups ( $p=0.038$ ) were identified at $90 \%$ of the confident level. Thus, the null hypothesis of non-moderating effect of relationship age on the relationship between call-club benefits and customer loyalty rejected at significant level 0.10. Further, the multiple group analysis results statistically indicate a significant standard regression weights of 0.60 for high relationship age and standard regression weights of 0.64 for low relationship age. This implies an increasing higher level of explanatory power with customer loyalty and perceived call-club benefits with lower level of relationship age. Summary of results are shown below in Table 3.

Table 3. Regression weights of the relationship among call-club benefits and customer loyalty based on subscriber's relationship age

\begin{tabular}{|c|c|c|c|c|c|}
\hline & \multicolumn{5}{|c|}{ Regression Weights } \\
\hline & \multicolumn{4}{|c|}{ Unconstrained } & Structural weights \\
\hline & Estimate & S.E. & C.R. & $\mathbf{P}$ & Estimate \\
\hline Low Relationship Age & 1.106 & .221 & 5.006 & *** & .642 \\
\hline High Relationship Age & 0.729 & .093 & 7.830 & *** & .601 \\
\hline
\end{tabular}

*** absolute $p$ value is less than 0.001

Source: Authors' own research.

H4. Mobile subscribers' usage of mVoIP applications positively moderates the positive effect of perceived call-club benefits and customer loyalty in mobile telecommunication.

The sample consists $50.9 \%$ subscribers using mVoIP applications to communicate with each other. Moderating effect of such application usage on the relationship between perceived call-club benefits and customer loyalty was tested using multiple group path analysis in AMOS. Two subscriber groups were identified and named as mVoIP users and non-users based on their usability of mVoIP applications. Test results indicate non-significant difference among these two groups $(p=0.379)$ at significant level of 0.05. Thus, there is not enough evidence to reject the null hypothesis that relates to the moderating effect on the relationship between perceived call-club benefits and customer loyalty at the significant level 0.05. Even two groups are not different statistically, the multiple group analysis results indicate statistically significant relationship with standard regression weights of 0.64 among mVoIP users and standard regression weights of 0.58 among mVoIP non-users. Analysis results are shown in below Table 4. 
Table 4. Regression weights of the relationship among perceived call-club benefits $s$ and loyalty based on subscriber's usage of mVoIP applications

\begin{tabular}{|c|c|c|c|c|c|}
\hline & \multicolumn{5}{|c|}{ Regression Weights } \\
\hline & \multicolumn{4}{|c|}{ Unconstrained } & \multirow{2}{*}{$\begin{array}{c}\text { Structural weights } \\
\text { Estimate }\end{array}$} \\
\hline & Estimate & S.E. & C.R. & $\mathbf{P}$ & \\
\hline mVoIP users & .747 & .110 & 6.763 & *** & .639 \\
\hline mVoIP non-users & .904 & .145 & 6.229 & $* * *$ & .584 \\
\hline
\end{tabular}

*** absolute $p$ value is less than 0.001

Source: Authors' own research.

H5. Mobile subscribers' usage of multiple mobile connections moderates the positive effect of perceived call-club benefits and customer loyalty in mobile telecommunication.

To test the moderating effect on the above-mentioned relationship, multiple group path analysis was employed. For the analysis, subscribers were identified as multiple connection users and non-users. Multiple connection users group consists of $49 \%$ of subscribers in the sample. According to the test results, non-significant difference among these two groups was identified at the 95\% confident level, chi-square (1) = $2.578, \mathrm{p}=0.108$. Thus, statistically there is not enough evidence to reject the null hypothesis relating to the moderating effect on the relationship between perceived call-club benefits and customer loyalty at the significant level 0.05. Even though the two groups are not statistically different, multiple group analysis results indicate statistically significant standard regression weights of 0.64 among multiple mobile connection users and standard regression weights of 0.59 among non-users. This implies an increasing higher level of explanatory power with customer loyalty and perceived call-club benefits based when mobile subscribers use multiple connections. Results of this analysis are summarized below in Table 5.

Table 5. Regression weights of the relationship among perceived call-club benefits $s$ and loyalty based on subscriber's multiple connection usage

\begin{tabular}{|c|c|c|c|c|c|}
\hline & \multicolumn{5}{|c|}{ Regression Weights } \\
\hline & \multicolumn{4}{|c|}{ Unconstrained } & Structural weights \\
\hline & Estimate & S.E. & C.R. & $\mathbf{P}$ & Estimate \\
\hline Multiple Connection User & .695 & .103 & 6.737 & $* * *$ & .641 \\
\hline Non-User & .982 & .157 & 6.256 & *** & .592 \\
\hline
\end{tabular}

Source: Authors' own research.

\section{Conclusions and implications}

As the mobile market moves towards the platform supplier for data channels which predict extensive future profit generation, mobile firms need to have healthy customer base to gain future market opportunities due to customers' acceptance of the internet based services than telephony facilities. As a result, many marketing strategies have been implemented to retain their customers within the network than ever before. Among those strategies, many strategies have focused on creating local network effects which is commonly used in the mobile telecommunication industry to 
lock-in subscribers within the network. Thus, this study focuses on call-clubs, one of factors which assist to institute local network effects in mobile telecommunication.

The primary purpose of this study was to investigate the relationship between perceived call-club benefits which caused or enforced local network effect and customer loyalty in mobile telecommunication. Further analysis was carried out to identify how subscribers' monthly spending and relationship age effect on the above relationship in the Sri Lankan mobile telecommunication context. Also, two of the most common technological advancements which are independent from the service provider, namely mVoIP application usage and multiple connection usage, and its effect on above relationship were also examined.

According to the analysis, the model shows a fairly high level of explanatory power with customer loyalty and perceived call-club benefits which indicate customers' preference towards the service provider when most frequently contacting parties are using the same network. This implies that the benefits received as a result of another set of customers in the same network are highly valued by most of the subscribers and it can play a key role to retaining subscribers even in todays' highly penetrated, technologically advanced market place. Thus, this scenario can be further utilized by developing specific strategies based on offering call-clubs benefits to retain subscribers within the service provider for a longer period of time which will be a key to win future markets.

Moderating effect analysis on subscriber's monthly spending shows a much stronger bond among perceived call-club benefits and customer loyalty when subscriber's monthly mobile expenditure is low. Thus, this low spending subscribers group can be identified as a price sensitive group. Due to this group of subscribers' concern on on-net benefits, they prefer to retain in same network for longer period of time. With time, they become loyal to the service provider. Thus, service providing companies need to highly focus on this group of customers to create a stronger relationship within the company in the future. Hence, family call plans based on lower on-net call rates may help service providers to retain many subscribers within the network and to create a stronger, competitive customer base even in the future. From a relationship age perspective, lower the relationship age, a higher level of explanatory power with customer loyalty and perceived call-club benefits have been identified. It implies that recently joined subscribers are seeking higher call-club benefits and with the benefits received, they can become loyal to the customers. In other word, this indicates potential customers' call-club benefit preference when selecting a service provider. Hence, call-club benefit focused strategies can be utilized not only to retain subscribers but also gain new ones to the network. As relationship age is a key to customer loyalty, service providers are needed to focus on recently joined customers. Offering higher benefits to this group of customers based on their frequently contacting parties will be profitable to the company as they are used to setup a higher bond with service provider. Thus, it would be a profitable investment for a future customer base.

From a technological advancement perspective, Internet based voice calling facility and multiple connection access facility were considered. Interestingly a significant difference was identified among the subscribers who are using more than 
one connection. Further, multiple connection users have shown a strong link between call club benefits and customer loyalty relationship than single connection users. This provides strong evidence for customer's expectations on call-club benefits. Subscribers intended to connect with more service providers to optimize the call-club benefits received from all the service providers. As this helps to create strong bond with customer loyalty, service providers have to highly concentrate on call-club benefits if they need to set sustainable customer base. Even the mVoIP application users have shown a higher level of explanatory power with customer loyalty and perceived call-club benefits than non-users. This also indicates price sensitivity among customer base. Subscribers use the internet based voice calling facilities as it is less costly than telephony. So, those customers are price sensitive and they also have a higher link with the main service provider and are also concerned on benefits received from call clubs.

In conclusion, perceived benefits of call-clubs play a major role in mobile telecommunication even in the technologically advance environment. As mobile subscribers are price sensitive, marketing strategies focusing on call-club benefits would be fascinating one for service providers to retain their customers within the network. Also, it may be a factor for potential customers to get link with the firm. Thus, call-clubs in mobile telecommunication helps to develop healthy customer based to grab future market opportunities even in technologically advanced, highly penetrated markets.

\section{Acknowledgements}

The authors of this study are grateful to the National Natural Science Foundation of China for sponsoring to carry out this research study under the grant 71272125 and 71672068.

\section{References}

Ahmad, R. and Buttle, F. (2002), "Customer retention management: A reflection of theory and practice", Marketing Intelligence and Planning, Vol. 20, No. 3, pp. 149-161.

Amin, S.M., Ahmad, U.N.U. and Hui, L.S. (2012), "Factors Contributing to Customer Loyalty towards Telecommunication Service Provider", Procedia - Social and Behavioral Sciences, Vol. 40, pp. 282 - 286.

Boakye, K.G. (2015), "Factors influencing mobile data service (MDS) continuance intention: An empirical study", Computers in Human Behavior, Vol. 50, pp. 125131.

Bove, L.L., Pervan, S.J., Beatty, S.E. and Shiu, E. (2009), "Service worker role in encouraging customer organizational citizenship behaviors", Journal of Business Research, Vol. 62, No. 7, pp. 698-705.

Central Bank of Sri Lanka: Annual Report - 2014, (2014), available at: www.cbsl.gov.lk/ htm/english/10_pub/p_2.html (accessed July 16th, 2016)

Chen, Y.H., Tseng, M.L., Lin, R.J., (2010), "Evaluating the customer perceptions on inflight service quality”, African Journal of Business Management, Vol. 5, No. 7, pp. 2865-2873. 
Dick, A. and Basu, K. (1994), "Customer loyalty: Toward an integrated conceptual framework", Academy of Marketing Science, Vol. 22, No. 2, pp. 99-113.

Farrell, J., and Klemperer, P. (2007), "Co-ordination and Lock-In: Competition with switching costs and network effects", in M. Armstrong and R. Porter (eds.) Handbook of Industrial Organization, pp. 3-23, Elsevier.

Fornell, C. (1992), "A national customer satisfaction barometer: The Swedish experience", Journal of Marketing, Vol. 56, pp. 6-21.

Fornell, C. and Larcker, D.F. (1981), "Evaluating structural equation models with unobservable variables and measurement error", Journal of Marketing Research, Vol. 18, No. 1, pp. 39-50.

Fullerton, G. (2005), "The impact of brand commitment on loyalty to retail service brands", Canadian Journal of Administrative Sciences, Vol. 22, No. 2, pp. 97-110.

Garbarino, E. and Johnson, M.S. (1999), "The different roles of satisfaction, trust, and commitment in customer relationships", Journal of Marketing, Vol. 63, pp. 7087.

GSM Association (2016), The mobile economy 2016, available at: www.gsmamobile economy.com/ (accessed August 27th, 2016).

Hallowell, R. (1996), “The relationship of customer satisfaction, customer loyalty and profitability: an empirical study", International Journal of Service Industry, Vol. 7, No. 4, pp. 27-42.

Harris, L.C. and Goode, M.M.H. (2004), "The four levels of loyalty and the pivotal role of trust: A study of online service dynamics", Journal of Retailing, Vol. 80, No. 2, pp. 139-158.

Haucap, J. and Heimeshoff, U. (2011), "Consumer behavior towards on-net/off-net price differentiation", Telecommunications Policy, Vol. 35, pp. 325-332.

Johnson, M.D., Herrmann, A. and Huber, F. (2006), "The evolution of loyalty intentions", Journal of Marketing, Vol. 70, pp. 122-132.

Jones, T. and Taylor, S.F. (2007), "The conceptual domain of service loyalty: how many dimensions?", Journal of Services Marketing, Vol. 21, No. 1, pp. 36 - 51.

Joreskog, K.G. and Sorbom, D. (1993), LISREL 8: A Guide to the Program and Applications, Scientific Software International, Chicago.

Karacuka, M, Haucap, J. and Heimeshoff, U. (2011), "Competition in Turkish mobile telecommunications markets: Price elasticities and network substitution", Telecommunications Policy, Vol. 35, pp. 201-210.

Karjaluoto, H., Jayawardhena, C., Leppaniemi, M., and Pihlstrom, M. (2012), "How value and trust influence loyalty in wireless telecommunications industry", Telecommunications Policy, Vol. 36, pp. 636-649.

Kerin, R.A., Hartley, S.W. and Rudelius, W. (2009), Marketing, McGraw-Hill, Boston.

Kim, M., Park, M., and Jeong, D. (2004), "The effects of customer satisfaction and switching barrier on customer loyalty in Korean mobile telecommunication services", Telecommunications Policy, Vol. 28, pp. 145-159.

Kotler, P. and Keller, K.L. (2006), Marketing Management, Prentice Hall, Upper Saddle River. 
Krishnamurthi, L. and Raj, S.P. (1991), "An empirical analysis of the relationship between brand loyalty and consumer price elasticity", Marketing Science, Vol. 10, No. 2, pp. 172-83.

Kumar, V. and Reinartz, W. (2006), Customer relationship management: A databased approach, John Wiley, New York.

Kumar, V., Shah, D. and Venkatesan, R. (2006), "Managing retailer profitability-one customer at a time”, Journal of Retailing, Vol. 82, No. 4, pp. 277-294.

Lam, S.Y., Shankar, V., Erramilli, M.K. and Murthy, B. (2004), "Customer value, satisfaction, loyalty, and switching costs: an illustration from a business-tobusiness service context", Journal of the Academy of Marketing Science, Vol. 32, No. 3, pp. 293-311.

Lee, D., Moon, J., Kim, Y.J., and Yi, M.Y. (2015), "Antecedents and consequences of mobile phone usability: Linking simplicity and interactivity to satisfaction, trust, and brand loyalty", Information and Management, Vol. 52, pp. 295-304.

Li, M. and Robert, D.G. (2011), "A mediating influence on customer loyalty: The role of perceived value", Journal of Management and Marketing Research, Vol. 7, pp. 112.

Liikanen, J., Stoneman, P., and Toivanen, O. (2004), “Intergenerational effects in the diffusion of new technology: The case of mobile phones", International Journal of Industrial Organization, Vol. 22, pp. 1137-1154.

Maicas, J.P., Polo, Y., and Sese, F.J. (2009), "The role of (personal) network effects and switching costs in determining mobile users' choice", Journal of Information Technology, Vol. 24, pp. 160-171.

Mak, B.L. and Sockel, H. (2001), "A confirmatory factor analysis of IS employee motivation and retention", Information and Management, Vol. 38, pp. 265-76.

Mullen, M.R. (1995), "Diagnosing measurement equivalence in cross-national research", Journal of International Business Studies, Vol. 26, No. 3, pp. 573-596.

Oliver, R. (1993), "Cognitive, affective, and attribute bases of the satisfaction response", Journal of Consumer Research, Vol. 20, No. 3, pp. 418-430.

Oliver, R. L. (1997), Satisfaction: A behavioural perspective on the customer, McGrawHill, New York.

Reichheld, F.F. and Sasser, W.E. (1990), "Zero defections. Quality comes to services", Harvard Business Review, Vol. 68, No.5, pp. 105-111.

Russell-Bennett, R., McColl-Kennedy, J.R., and Coote, L.V. (2007), "The relative importance of involvement and satisfaction on brand loyalty in a small business services setting", Journal of Business Research, Vol. 60, No. 12, pp. 1253-1260.

Serkan, A. and Gorhan, O. (2004), "The analysis of antecedents of customer loyalty in the turkish mobile telecommunication market", European Journal of Marketing, Vol. 39, pp. 910-925.

Sobolewski, M. and Czajkowski, M. (2012), "Network effects and preference heterogeneity in the case of mobile telecommunications markets", Telecommunications Policy, Vol. 36, pp. 197-211. 
Soderlund, M. (2003), "The retrospective and the prospective mind and the temporal framing of satisfaction", European Journal of Marketing, Vol. 37, No.10, pp. 1375-1390.

Srinuan, P., Srinuan, C., and Bohlin, E., (2014), “An empirical analysis of multiple services and choices of consumer in the Swedish telecommunications market", Telecommunications Policy, Vol. 38, pp. 449-459.

Verhoef, P.C. (2003), "Understanding the effect of customer relationship management efforts on retention and customer share development", Journal of Marketing, Vol. 67, pp. 30-45.

Zeithaml, V.A., Berry, L.L., and Parasuraman, A. (1996), "The behavioural consequences of service quality”, Journal of Marketing, Vol. 60, No. 2, pp. 31. 